\title{
New approach in studying cardiac muscle cell injury*
}

\author{
G. RONA $\dagger$ \\ M.D., Ph.D
}

\author{
M. BOUTET \\ M.D., Ph.D.
}

\author{
I. HÜTTNER \\ M.D., Ph.D. \\ Pathology Institute, McGill University, Montreal, Canada*
}

\begin{abstract}
Summary
A new approach for investigating the mechanisms and evolution of cardiac muscle cell injury was presented by applying fine structural extracellular protein tracers in the catecholamine-induced cardiac muscle cell injury model. The results with these diffusion tracers indicated striking functional changes at the level of coronary microcirculation followed by early permeability alteration of cardiac muscle cell membranes, thus suggesting the role of these factors in myocardial changes which develop without narrowing or obstruction of coronary arteries.
\end{abstract}

DURING the past 15 years, investigations of our research group concerned themselves with the study of myocardial reaction and adaptation to insult under various experimental conditions (Rona, 1971). Recently ultrastructural and functional correlative studies carried out with catecholamines with continuous low dose $(4-6 \mu \mathrm{g} / 100 \mathrm{~g}$ body $\mathrm{w} / \mathrm{min})$ infusion showed that isoproterenol and norepinephrine produced irreversible cardiac muscle cell lesion. On one hand, the cardiac muscle cell lesions produced by various catecholamines have certain similar morphological features which were related to their common metabolic effect (mitochondrial respiration, glycogenolysis, fatty acid mobilization, electrolyte shift). On the other hand, their diverse effect on the myofilaments and the interstitial reaction indicated differences in the pathogenesis of the myocardial lesions elicited by the two catecholamines. Whereas isoproterenol induced primarily myofilament hypercontraction and contraction bands, lytic lesions predominated in the norepinephrine-induced cardiac muscle cell changes. Moreover, rats treated with norepinephrine showed early and marked interstitial oedema, whereas in rats treated with isoproterenol, the evolution of oedema was delayed by hours (Boutet, Hüttner and Rona, 1973, 1974).

* Grant No. MT-3635.

$\dagger$ Department of Pathology, McGill University, Montreal.
Some of the structural differences were related to the diverse circulatory effect of the two catecholamines. Isoproterenol is a depressor amine, while norepinephrine is a strong pressor agent. Whereas several investigations dealt with the role of vascular factors in the pathogenesis of myocardial lesions produced by catecholamines, little attention was paid to the functional effect of these agents on the local coronary microcirculation. Extracellular fine structural protein tracers can be utilized with advantage to investigate how catecholamines affect the functional state of coronary capillaries. In our laboratory, peroxidase and ferritin were used for such microcirculatory studies (Hüttner, Boutet and More, 1973a, b; Hüttner et al., 1973). Peroxidase molecules that have a diameter of approx. $50 \AA$ and molecular weight of 40,000 traverse the endothelial barrier through intercellular clefts and by plasmalemmal vesicles. Ferritin which has a diameter of approx. $110 \AA$ and molecular weight of 500,000 is transported exclusively by plasmalemmal vesicles of the coronary capillary endothelium.

Catecholamines were infused under ether anaesthesia in a dose of 4-6 $\mu \mathrm{g} / 100 \mathrm{~g}$ body $\mathrm{w} / \mathrm{min}$, while the systemic blood pressure was recorded on a polygraph. Saline-treated animals were used as controls for tracer experiment. The observation of delayed phase of interstitial oedema in the isoproterenol experiment necessitated the introduction of another experimental group in which isoproterenol was given subcutaneously in a dose of $8.5 \mathrm{mg} / 100 \mathrm{~g}$ body wt and the tracers were injected at the time of the delayed oedema, i.e. $90 \mathrm{~min}$ following isoproterenol injection. Diffusion tracers were injected at various time intervals before sacrificing the animals by perfusion of aldehyde fixative through the coronary capillaries. Horseradish peroxidase was injected in a dose of $10 \mathrm{mg} / 100 \mathrm{~g}$ body wt, whereas the dose of ferritin was $100 \mathrm{mg} / 100 \mathrm{~g}$ body wt.

Figure 1 shows the polygraph records of carotid artery pressure from control, as well as norepinephrine, and isoproterenol-infused rats. Note that 

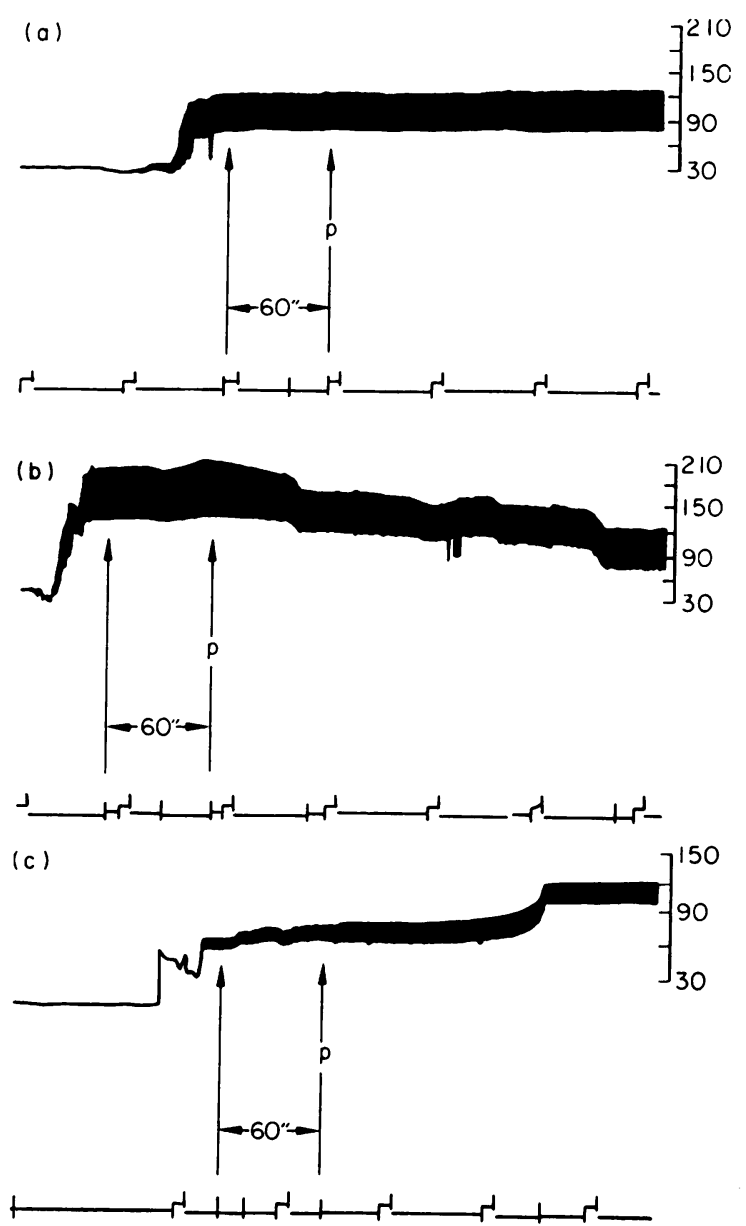

FIG. 1.

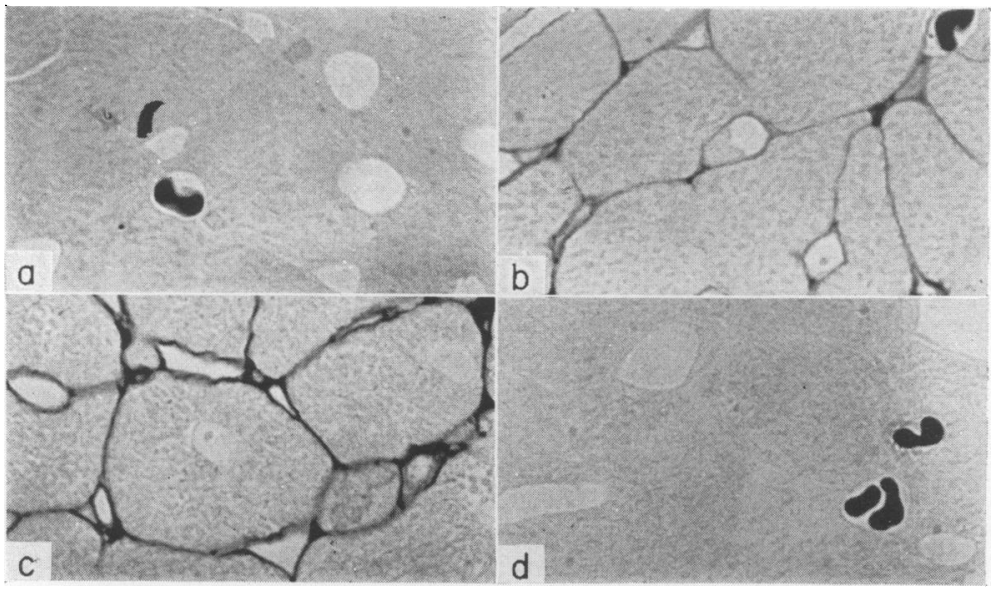

FIG. 2. 
the records read from right to left. Parallel arrows indicate the peroxidase circulation time which, in this experiment, was $60 \mathrm{sec}$. Similar recordings are obtained with ferritin. Continuous intravenous infusion of norepinephrine produces a rise of blood pressure from the control $115 \pm 15 \mathrm{mmHg}$ to $190 \pm 20 \mathrm{mmHg}$. This high blood pressure level remained constant during the circulation time of peroxidase. Following isoproterenol infusion there is an immediate drop of arterial blood pressure to $70 \pm 15 \mathrm{mmHg}$. The ultrastructure of endothelial cells was comparable with that of controls in animals treated with catecholamines under the selected experimental conditions. Studies with protein tracers revealed, however, striking functional changes at the level of microcirculation.

Figure 2 presents light microscopic picture of right ventricular myocardium from the selected experimental groups. Upper set of pictures made after $60 \mathrm{sec}$, and the lower pictures after $6 \mathrm{~min}$ circulation time of the tracer. As compared with the negative control (a), the myocardial interstitium shows diffuse staining by reaction product following NE-induced high blood pressure (b). At 6 min there is uniform distribution of the tracer in control myocardial interstitium (c). The tracer is, however, absent following isoproterenol induced low blood pressure (d).

Figure 3 presents the same experimental arrangement and fine structural localization of peroxidase reaction product. In control, the tracer is localized in the lumen of the capillary, in lumenal plasmalemmal vesicles and in the lumenal side of interendothelial clefts, but the myocardial interstitium is negative for peroxidase (a). In contrast to the negative control, intensive reaction is obtained all along

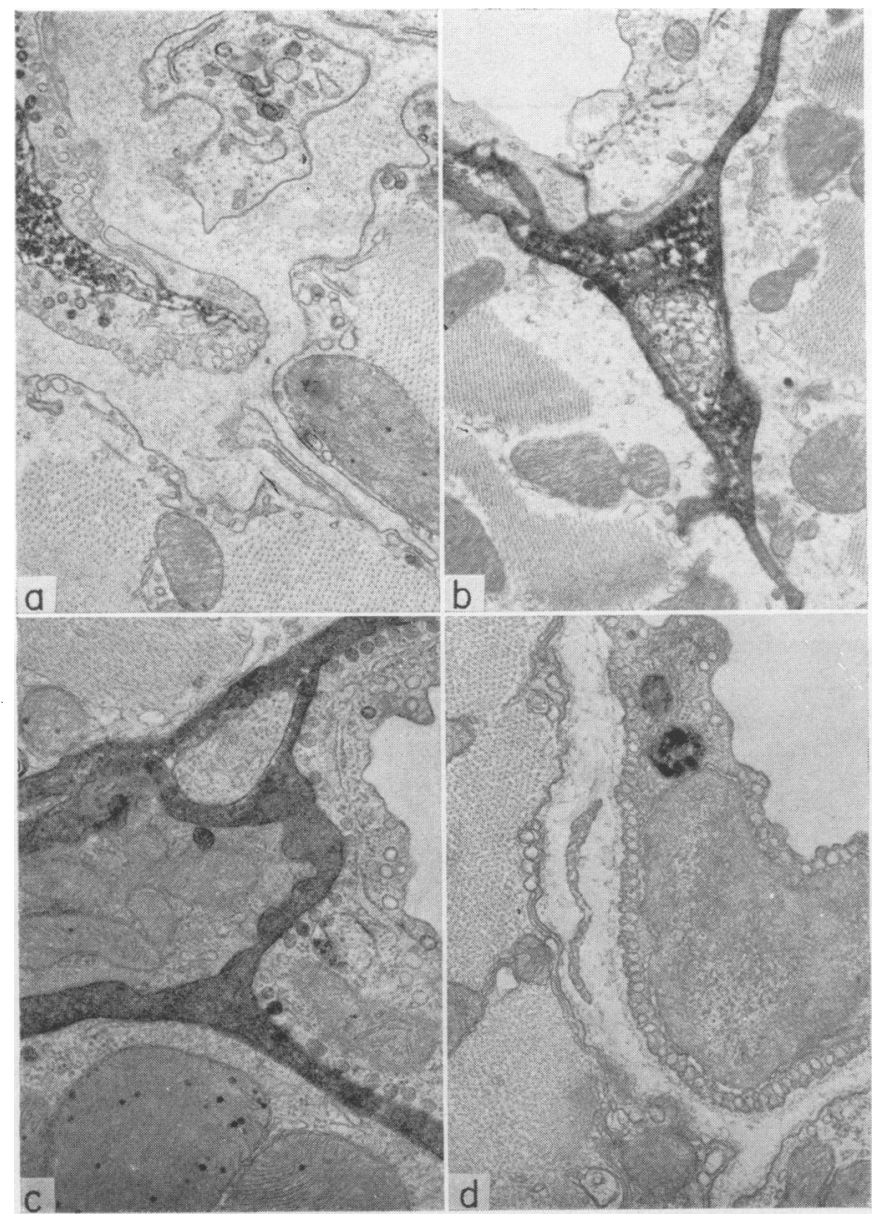

Fig. 3. 


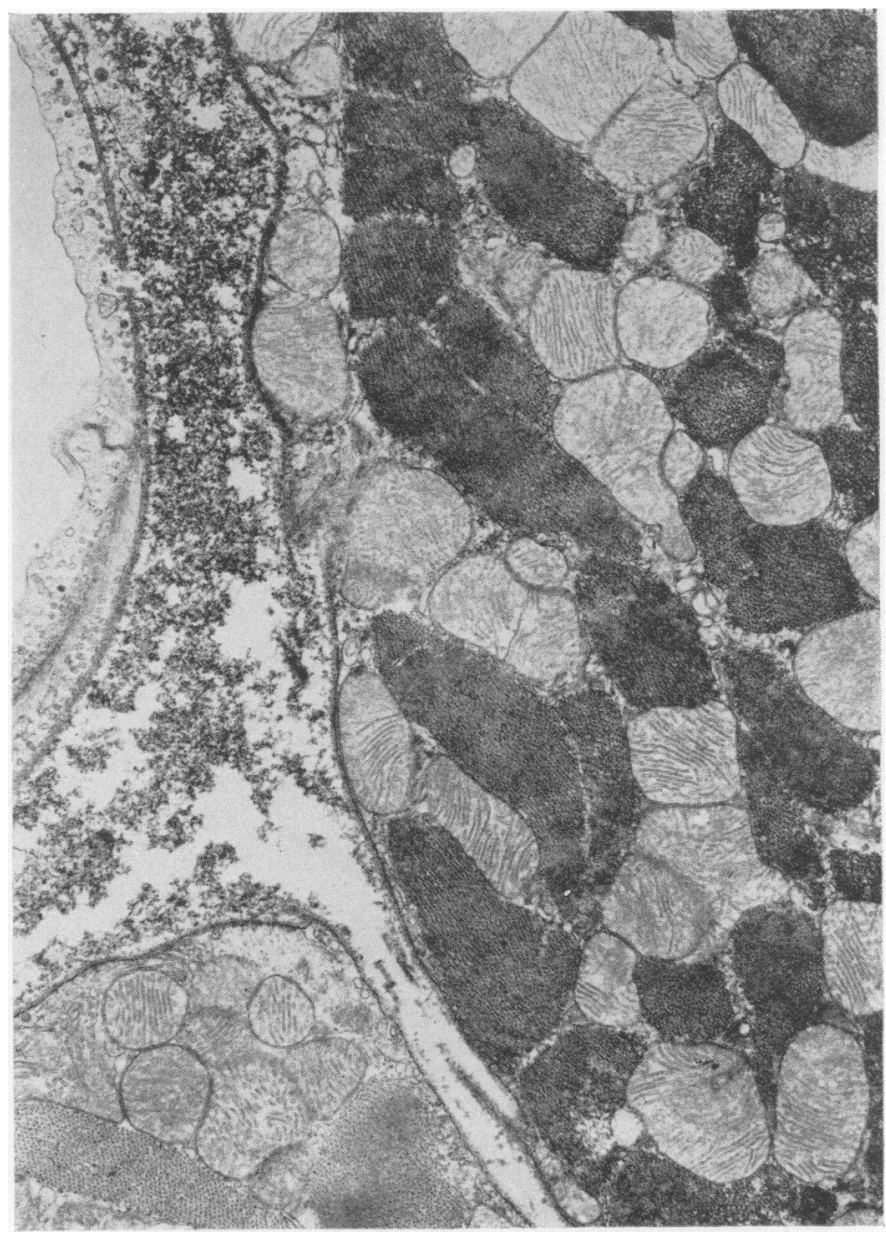

FIG. 4.

interendothelial clefts, ablumenal vesicles and in the myocardial interstitium following identical $60 \mathrm{sec}$ peroxidase circulation time in rat with norepinephrine-induced high blood pressure (b). Six minutes following peroxidase injection, peroxidase reaction product is already localized in the interstitium of controls (c). Following identical 6 min circulation time from rat with isoproterenol-induced low blood pressure, peroxidase labels some large endothelial vesicles but no reaction product is discernible in the myocardial interstitium, indicating uptake but no transendothelial transfer of the tracer (d).

Figure 4 shows that as early as 10 min following norepinephrine infusion the sarcoplasm of some cardiac muscle cells is also positive for peroxidase, indicating that the sarcoplasmic membrane of these cells became permeable to the tracer. Note that peroxidase within the sarcoplasm is deposited upon and bound selectively to myofilaments. These cells otherwise present normal ultrastructure. The same findings were present in isoproterenol studies in the recuperation phase when the arterial blood pressure returned towards normal levels.

Pressor and depressor catecholamines similarly affected the transport of the large molecular tracer ferritin which enters the myocardial interstitium exclusively by plasmalemmal vesicles (Fig. 5). Upper set of pictures are electron micrographs from myocardium $20 \mathrm{~min}$ after ferritin injection. As compared with control (a) there was an increased number of ferritin molecules in the myocardial interstitium following norephinephrine infusion (b). Whereas the difference between the control and the norepinephrine-treated rats for ferritin was less striking than for peroxidase transport, at low blood pressure levels produced by isoproterenol, there was a striking 


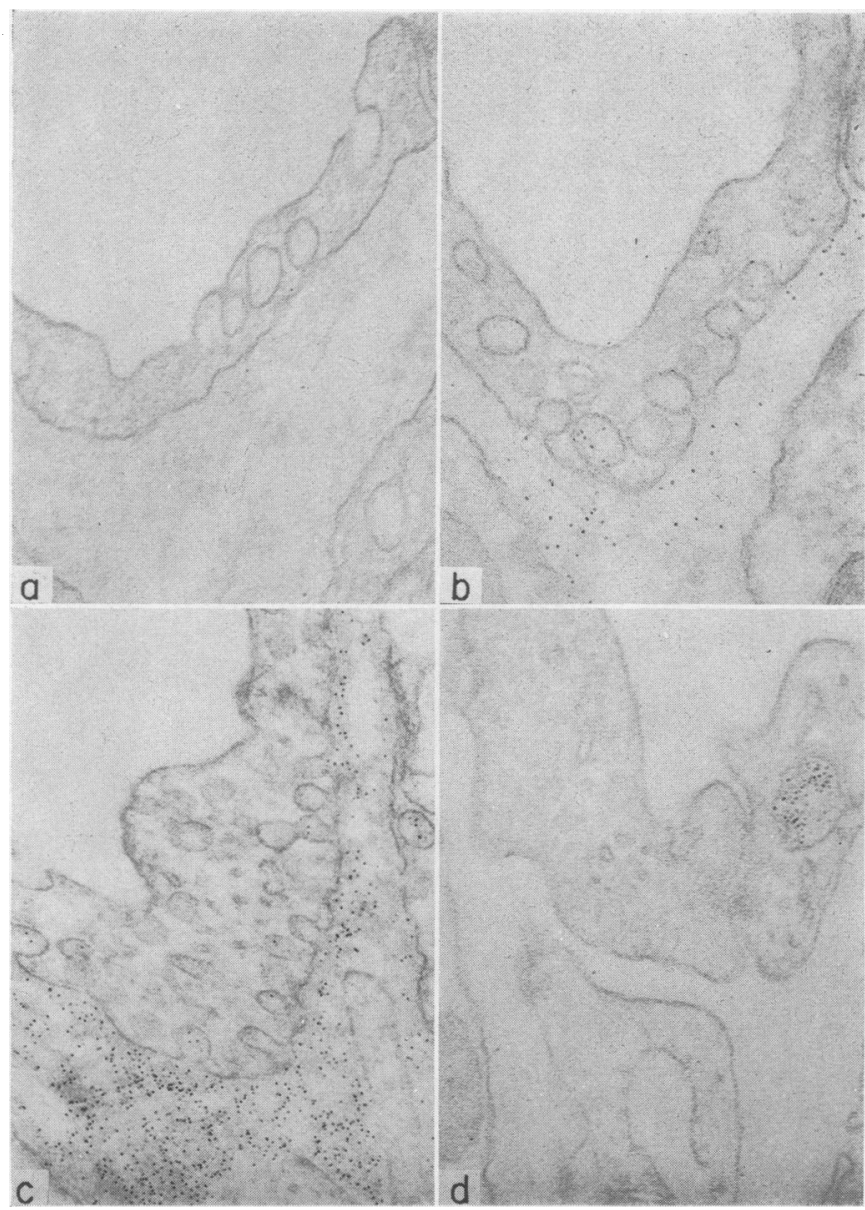

FIG. 5.

diminution of ferritin molecules in the myocardial interstitium (c, control; $d$, isoproterenol, $60 \mathrm{~min}$ circulation time).

\section{Conclusions}

(1) Structural-functional correlative studies suggest a relationship between blood pressure changes, coronary transendothelial protein transport and alteration of cardiac muscle cells following comparable low dose intravenous infusion of pressor and depressor catecholamines.

(2) Isoproterenol, a depressor amine, induced a diminution of transendothelial passage of fine structural protein tracers, that was more marked for peroxidase than for ferritin. This phenomenon was reversible with return to normal blood pressure. Norepinephrine, a pressor amine, augmented the transendothelial passage of both peroxidase and ferritin.
(3) In isoproterenol model, decreased transendothelial transport and myocardial perfusion may indicate the role of an additional factor in the complex mechanism whereby this catecholamine brings about myocardial hypoxia. Observation in the recuperation phase furnished further component in the chain of events leading to cardiac muscle cell injury. Following return of blood pressure towards normal levels, increased sarcolemmal permeability was reflected by the intrasarcoplasmic presence of extracellular diffusion tracers. Similar membrane alteration was observed in the early stage of norepinephrine experiment. These observations suggest that early membrane permeability change may be the key factor in catecholamine myocardial injury.

The experimental protocol presented may give further information concerning the development and evolution of cardiac muscle cell lesions produced by other types of injury. It is possible to hypothesize, in 
the meantime, that in humans subjected to stress, release of excessive amount of catecholamine may also produce functional alteration of coronary capillaries. Subsequent change of sarcolemmal membrane permeability leads to intrasarcoplasmic deposition of proteinaceous substances. The evolution of cardiac muscle cell injury in heart muscle following administration of catecholamines was the subject of a previous presentation at the 6th Annual Meeting of the International Study Group for Research in Cardiac Metabolism in Freiburg. The results of the functional-correlative study outlined in the present paper suggest that coronary microcirculatory changes and membrane permeability alteration represent important components in a common mechanism that leads to myocardial changes which develop without narrowing or obstruction of coronary arteries.

\section{References}

Boutet, M., Hüttner, I. \& RonA, G. (1973) Aspect microcirculatoire des lésions myocardiaques provoquées par l'infusion de catécholamines. Etude ultrastructurale à l'aide de traceurs de diffusion. 1. Isoprotérénol. Pathologie et biologie (Paris), 8, 811.

Boutet, M., Hüttner, I. \& Rona, G. (1974) Aspect microcirculatoire des lésions myocardiques provoquées par l'infusion de catécholamines. Etude ultrastructurale à l'aide de traceurs de diffusion. 2. Norépinéphrine. Pathologie et biologie (Paris), 5, 377.

Hüttner, I., Boutet, M. \& More, R.H. (1973a) Studies on protein passage through arterial endothelium. I. Structural correlates of permeability in rat arterial endothelium. Laboratory Investigation, $28,672$.

HüttNer, I., Boutet, M. \& More, R.H. (1973b) Studies on protein passage through arterial endothelium. II. Regional differences in permeability to fine-structural protein tracers in arterial endothelium of normotensive rats. Laboratory Investigation, 28, 678.

Hüttner, I., Boutet, M., Rona, G. \& MORE, R.N. (1973) Studies on protein passage through arterial endothelium. III. Effect of blood pressure levels on the passage of finestructural protein tracers through rat arterial endothelium. Laboratory Investigation, 29, 536.

RoNA, G. (1971) Cardiac adaptation to insult. Symposium on Metabolism and disease, Health and Welfare Canada, p. 50. Ottawa, Canada. 